\title{
MOMENTOS DA CONDUTA
}

\author{
RENÉ DOTTI \\ Auxiliar de Ensino de Direito Penal
}

S U MÁ R IO :

1. Comemorativos; 2. Objeções à diferença entre crime consumado e exaurido; 3 . Referência de MANZINI; 4. Desimportância da distinção em face do conceito analítico do crime; 5 . A chamada "existência natural da ação" para limitar o fático e o jurídico; 6. Sucessão dos efeitos postevento; 7. Crime esgotado e progressivo; 8 . Da progressão criminosa; 9. Suas categorias; 10. Hipóteses de antefato e postfato impuníveis no Código Penal brasileiro; 11 . Tratamento do problema; 12 . Sugestão.

1. Ao criticar as consequências da conduta como suporte elementar do delito, BARSANTI desenvolveu a distinção formulada por FARANDA entre crime consumado e exaurido (1) segundo a qual o acontecer ilícito transcendia a fase da consumação para manter relevância jurídica na medida em que cumpria a finalidade posta a serviço da ação.

Assim, o crime de incendio se consideraria esgotado desde que - fogo lançado à casa a destruisse completamente conforme o desejo do autor ou a prestação do falso testemunho tivesse a eficácia de gerar o prejuizo natural proposto pelo delinquente.

FERRI aprovou a distinção para colocá-la ao lado dos crimes formais e materiais, considerados êstes como a correspondência entre a vontade do agente e a determinação de um resultado perceptível no mundo exterior. (2).

A consumação se constituiria em pura violação jurídica (contraste entre comportamento e norma) enquanto o esgotamento representaria a derradeira etapa, em têrmos de efeito, da atividade humana. 
CARRARA partia da divisão entre delito perfeito ("quando o fato alcançou sua objetividade jurídica, isto é quando violou o direito protegido pela lei penal, que constitui a essencialidade da infração correspondente") e imperfeito quando, ausente a violação houve a periclitação do direito, para anunciar que o chamado delito perfeito poderia ser desdobrado em "simplesmente perfeito" e "perfeito esgotado" ou seja, quando "tenha produzido todos os efeitos danosos que fossem consequência da violação e aos quais visava o agente, de modo que êste não mais possa impedir semelhantes efeitos" (3).

Em sintonia com as lições de BARSANTI em "Del pentimento dei reati e suoi effetti giuridici" (Macerata, 1885) FLORIAN promoveu a separação, recolhendo elementos expostos por CARRARA, salientando que algumas ações não se detinham na "pura violação jurídica" mas geravam ulteriores consequências em obediência à vontade do agente, considerando como último momento do iter criminis, em alguns casos, a reparação do dano promovida pelo autor, quando possível. (4).

2. ROCCO (5), PAOLI (6) e muitos outros escritores, repudiaram tal distinção, ponderando com a inifinita série de efeitos que o delito pode acarretar mas que se não subsumem à ordem do Direito.

Discursando sôbre os efeitos naturais da ação, ANTOLISEI acentuou: "La distinzione degli effetti in diretti e indiretti, in inmediati e mediati, in prossimi e remoti, pertanto, non ha valore per il diritto penale. Essa può farsi solo attribuendo a quelle espressioni un significato speciale, diverso da quello che hanno dal punto di vista naturalistico". (7).

Tal posição consulta a realidade do conhecimento, pois sòmente uma parcela dos efeitos da ação ou de qualquer outro fenômeno, poderá ser alcançada pela percepção.

3. Apesar da propriedade com que se expungiu essa categoria de crime, não faltaram autores de excelente expressão que a validaram, como, por exemplo, MANZINI quando trata dos crimes instantâneos de efeitos permanentes, utiliza o vocábulo "esgotado" (8) considerado por GRISPIGNI como equívoca. (9).

4. Nos modernos estudos sôbre a teoria geral do delito, a classificação é desimportante, acentua HELENO CLAUDIO FRAGOSO (10) funcionando tão sòmente para estabelecer a quantidade da pena enquanto BETTIOL compreende, no sentido jurídico penal, exaurimento como sinônimo de consumação, admitindo o emprêgo da expressão no senso "econômico" para traduzir as consequências concretas que normalmente o ilícito penal se destina a produzir. (11). 
A mesma orientaçăo seguiu BATTAGLINI salientando a dificuldade na fixação do limite dos ulteriores efeitos da ação, quer no plano objetivo do dano, como no quadro subjetivo da vontade do autor, pois ou a intenção "coincide com o evento indicado pela lei (como o proveito entendido também em sentido econômico no estelionato) não tendo evidentemente relêvo, ou então não há coincidência, e também neste caso não interessa" (12).

O magistral COSTA E SILVA doutrinando a propósito da consumação, refere que a consecução do objetivo visado pelo agente é jurídicamente irrelevante (13).

5. Apesar da autoridade de MAURACH para quem "a ação é uma conduta humana, regida pela vontade orientada a um determinado resultado" salientando que o conceito naturalista encontra-se atualmente abandonado (14), parece-nos que a desconsideração do exaurimento como ełapa do fenômeno crime, dependerá da adoção nesta teoria que conceitua a ação como voluntário comportamento humano que produz modificação no mundo exterior.

E isto porque a ação concebida estritamente como suporte do crime tem uma existência que nasce com a projeção da vontade (desprendimento do mundo espiritual do autor) e termina com o ajustamento ao tipo, constituindo o evento. Daí usarmos a expressão "existência natural da ação" até a construção do fato típico (realização ou início de realizaçăo do tipo). Verificado o evento, a ação perde a qualidade natural para ganhar os coeficientes de valoração cultural.

A qualidade externa de desvalor será afirmada pela antijuridicidade enquanto a inspeção interna será promovida pela culpabilidade que declara a censurabilidade (ou reprovabilidade) bem como a capacidade, em têrmos de sanidade e maturidade mentais, que possibilitavam a eleição de conduta diversa.

Assim, vista a ação como posição de causa, conforme a orientação do Código Penal brasileiro (art. 11), o comportamento, como base do fato punível, completa-se desde que seja tìpicamente relevante. Por isso, afigura-se-nos como excelente a conclusão de HELENO CLAUDIO FRAGOSO: "Evento é a realização da conduta típica" ("Conduta Punível", 192).

Para nosso aviso, a inteligência do delito como ação tìpicamente antijurídica e culpável, prescinde da crítica da qualidade cultural da conduta (valoração decorrente do evento) contentando-se apenas com a voluntariedade de sua expressão, a qual, em última análise, se reduz à liberdade (no plano fisiológico) entre o fazer e o não fazer. 
Daí considerarmos o evento como limite entre o mundo fático e jurídico, facilitando a melhor compreensão didática do tema.

A teoria normativa da ação (incidência de valor social); a teoria sintomática (como expressão da personalidade do agente para indicar maior ou menor perigosidade) e a teoria finalista (o querer humano é finalidade, aparecendo sob a forma de um "dolo natural") não permitem a melhor fixação de dados para o desenvolvimento da tese no sentido de que o chamado crime exaurido desinteressa à problemática do delito.

6. Os acontecimentos ulteriores ao evento, como funcionalidade da ação, passam a compor o repertório de elementos que informarão a pena (ou medida de segurança) como ocorre, por exemplo, com o artigo 42 do Código Penal brasileiro que recomenda ao juiz a verificação das consequências do crime (sucessão objetivo-subjetiva do evento) para modelar a medida da sanção.

7. Neste momento é oportuna a distinção entre crime esgotado e progressivo. No primeiro, o comportamento mantém relevância após violar um imperativo de comando ou proibição contido na norma, mas para plasmar a resposta penal. No segundo, a conduta indicada pelo núcleo do tipo é consequência de atos que "se desenvolvem através da passagem de um tipo fundamental menos grave para outro de maior gravidade". (15) Trata-se de relação contida na estrutura interna do próprio tipo e não fora dêste com outro tipo anteriormente concretizado. (16) O exemplo comum é o do homicídio em relação às lesões corporais.

A distinção básica repousa no critério da chamada existência natural da ação. No crime exaurido, a conduta deixou de existir no sentido naturalístico desde que se adaptou ao tipo, perdendo sua qualidade física para merecer os juizos de desvalor (externo ou interno) procedidos pela antijuridicidade e culpabilidade, porém os seus efeitos serão reconhecidos, não mais em referência ao fato punível mas em atenção ao seu autor, no momento da atribuibilidade, considerada esta como a base geral da responsabilidade no dizer de MAURACH. Assim, o crime de lesão corporal gravíssima pela deformidade permanente (art. $129 \S 2 .^{\circ}$, IV do Cód. Penal) se consumou (evento) com a produção do estigma físico, porém, em têrmos de medida penal, se exauriu quando a vítima tenha sofrido as consequências sociais decorrentes da deformação e que correspondiam à vontade do autor.

No delito progressivo, o comportamento unitário do agente ultrapassa um tipo estagiário para alcançar outro de maior importância jurídica, resolvendo-se a hipótese do aparente concurso de leis, pelo princípio da consumação. (Major absorbet minorem). 
Em relação ao primeiro, consideram-se os efeitos da ação, postevento; no segundo, dois ou mais eventos se sucedem, construidos por uma só conduta através de sequência temporal de atos, os quais, na medida em que irão ofendendo bens de maior expressão, porém na mesma linha de desdobramento causal, vão sendo absorvidos até a construção do evento mais grave. Êste se constituirá no vetor para a constatação do único fato punível.

8. De maneira que nos pareceu equívoca, data venia, JIMENEZ DE ASÚA formula como hipótese de crime esgotado a venda de coisa furtada: "Vender la cosa que hemos hurtado no podrá constituir un nuevo delito, ni aun en aquellos paises que consideran fraudulento enajenar el objeto que no nos pertenece. Venderlo no es otra cosa que agotar el hurto". (17).

O que aí se verifica é a progressão criminosa, ou seja, a plu. ralidade de ações típicas, observada uma entre elas uma afinidade em têrmos da vontade do agente, como ocorre no fato de alguém prati. car em outrém lesões corporais e, posteriormente, através de nôvo curso causal, determinar a morte da mesma pessoa.

Certamente o aspecto que impressionou o notável Mestre ASÚA, para reconhecer naquele episódio um delito exaurido, foi o alcance da vontade do delinquente que teria furtado para vender. Mas, o fim pretendido pelo agente deixa de se considerar como elemento do chamado crime exaurido, desdé que a realização do mesmo dependa de outro evento típico.

9. O fenômeno da progressão criminosa apresenta as categorias seguintes, conforme JOSÉ FREDERICO MARQUES: a) progressão criminosa em sentido estrito; b) fato antecedente não punível; c) fato sucessivo não punível (apud ANTOLISEl, "Manuale, Parte Generale, 1952 pág. 282).

E explicita: "Ocorre a progressão em sentido estrito quando aquilo que constituiria um crime progressivo desliga-se ou desfazse temporalmente. Um indivíduo fere a outro mas, ao depois, delibera matá-lo e o faz..." Existe o antefactum não punível, quando o fato menos grave serviu de meio para a prática do delito mais grave. Verifica-se o postfactum não punível quando um fato sucessivo menos grave é cometido, contra um mesmo bem pertencente à mesma pessoa, para a utilização de um fato antecedente e mais grave, e isto para dêste tirar proveito, mas sem produzir outra ofensa". (18)

10. Em nosso Código Penal, tais hipóteses do antefato e postfato impuníveis (straflose vor-und Nachtat, dos autores alemães) cabem, respectivamente, em relação aos delitos de petrechos para falsificação de moeda (art. 291) e moeda falsa (art. 289) e destruição, pelo próprio ladrão, da coisa furtada. (arts. 163 e 155). 
O uso de documento falso é impunível se o usuário foi o autor da falsificação, o mesmo sucedendo em relação à colocação da moeda falsa em curso, desde que promovido pelo agente da adulteração ou fabricação.

11. A doutrina do antefato e postfato impuníveis deveria ser estendida (independentemente da identidade do bem jurídico atacado e do sujeito passivo, como quer RANIERI (19) para regular determinados episódios do cotidiano criminal, a fim de se conjurar a severidade decorrente do reconhecimento do concurso material de delitos.

A respeito da falsificação documental para o cometimento posterior do estelionato, verbi gratia, existem decisões no sentido de reconhecer apenas o crime de falso: "Quando o único ardil empregado pelo agente consiste no uso do documento falso, o crime configurado é apenas o de falsidade". (Supremo Tribunal, 11 de maio de 1956 H.C. 33.856, rel. Min. NELSON HUNGRIA) (20).

No mesmo sentido: "Se a vantagem ilícita foi obtida com o uso, apenas, do documento falsificado, o crime é de falsidade e só haverá estelionato se houver uso de outro meio ou artifício fraudulento". (Tribunal de Justiça do Rio Grande do Sul. (21).

Em sentido inverso já se pronunciou, em 1959, o Supremo Tribunal, em acordão relatado pelo Ministro LUIZ GALLOTTI (22).

Pondera HELENO CLAUDIO FRAGOSO que a melhor doutrina e a jurisprudência estrangeiras de prestígio, se inclinam pelo reconhecimento da punição do postfactum, concluindo pelo concurso material. Porém, em face da gravidade da resposta penal, a comissão revisora do anteprojeto NELSON HUNGRIA excluiu expressamente o concurso com a instalação do seguinte texto: "Se o crime contra a fé pública fôr o único meio empregado na prática de outro crime, o agente responderá tão sòmente pela falsidade', mas com a pena aumentada de um a dois têrços" (23).

Mas, se o crime-meio fôr punido menos severamente que o crime-fim? Suponha-se a hipótese de falsificação de documento particular, cuja pena é menor que a aplicável ao falso de documento público (arts. 297 e 298 do Código vigente; 321 e 322 do anteprojeto) como meio para o cometimento de estelionato que atinja a fase de consumação. Em tal caso, o estelionato tem resposta penal mais grave (arts. 171 e 298 do Código atual; 183 e 322 do anteprojeto). Estaria correta a solução dada pela ilustrada comissão revisora, considerandose que neste caso o bem jurídico patrimônio tem maior repercussão penal que a fé pública?

Parece-nos que não, apesar da possibilidade da aplicação do 
quantum da majoração (um a dois terços) poder ultrapassar a sanção cabível para o delito fim.

12. Assim, a melhor técnica residiria em modificação do texto do anteprojeto, sugerindo-se o seguinte: "Se o crime contra a fé pública fôr o único meio empregado para a prática de outro crime, - agente responderá tão sòmente pelo crime mais grave, mas com a pena aumentada de um a dois têrços.".

$E^{\prime}$ de excelente oportunidade o tratamento normativo adotado pela egrégia comissão revisora, expungindo por disposição expressa as dúvidas relativas à temática da progressão criminosa no que tange ao anterior ou posterior acontecimento típico, como desdobra. mento da vontade do autor, através da sanção parcial.

1. BARSANTI ("Delito esaurito")

2. ENRIQUE FERRI ("Direito Criminal", pág. 523)

3. FRANCESCO CARRARA ("Programa de Direito Criminal", pág. 64)

4. EUGENIO FLORIAN ("Trattato di Diritto Penale", I, pág. 464)

5. A. ROCCO ("L’Oggetto del reato", pág. 328)

6. PAOLI ("Principii, II", pág. 7)

7. FRANCESCO ANTOLISEl ("L'Azione e l'evento nel reato", pág. 76)

8. VINCENZO MANZINI ("Tratado", pág. 100)

9. FILIPPO GRISPIGNI ("Diritto Penale Italiano", I, pág. 63 nota 2)

10. HELENO CLAUDIO FRAGOSO ("Conduta Punível", pág. 85)

11. GIUSEPPE BETTIOL ("Diritto Penale", pág. 438)

12. GIULIO BATTAGLINI ("Direito Penal, parte geral", pág. 211)

13. A. J. DA COSTA E SILVA ("Código Penal", pág. 75)

14. REINHART MAURACH (Tratado de Derecho Penal" I, pág. 182)

15. JOSÉ FREDERICO MARQUES ("Tratado de Direito Penal", 2.0 pág. 365)

16. SILVIO RANIERI ("Reato Progressivo e Progressione criminosa", págs. 13 e 14)

17. LUIS JIMENEZ DE ASÚA ("La Ley y el delito", pág. 620)

18. JOSÉ FREDERICO MARQUES, op e loc cit. conf. ALDO MORO.

19. SILVIO RANIERI ("Diritto Penale" Parte Generale, pág. 357)

20. REVISTA FORENSE, volume 171, pág. 335

21. DARCY ARRUdA MIRANDA ("Rep. de Jurisp. do Cód. Penal", IV pág. 494)

22. REVISTA BRASILEIRA DE CRIMINOLOGIA E DIREITO PENAL, n.॰ 13, pág. 132) 